Fildan P. ${ }^{1}$, Dantes E. ${ }^{1,2}$, Arghir O.C. ${ }^{1,2}$

\title{
Occupational exposure and lung cancer risk - Study in two different Romanian areas
}

${ }^{1}$ Clinical Pneumo phtisiology Hospital of Constanta

${ }^{2}$ Faculty of Medicine, University "Ovidius" Constanta

\section{ABSTRACT}

Lung cancer is the most frequent neoplasm worldwide and the incidence in Constanta County is in continuous increasing. Occupation as a cause of lung cancer is common. The authors examined the relation between occupation and lung cancer in two patient cohorts $f^{-} \cdot m$ different areas of Romania: Constanta and Valce 2005-2010, in Constanta and Valcea counties, 488 : 344 incident lung cancer cases were enrolled. Lifetin occupational histories (industry and coded by using standard internatir class cations and were translated into occupat known st A) or suspected (list B) to be associated h lup exposure excess of $14.6 \%$ patien. $\mathrm{m}$ Constanta ever employed in occur ons known to associated with lung cancer (lis found, with largest contributions from ne oil i ery and shpbuilding industries No or all excess was dor list B with the exception of $s$ and truck drivers ( $1, y$ ) and launderers and dry $c$ ners (wo in both groups of patients. These res indic that past exposure to occupational carcinogens ans an im rant determinant of lung

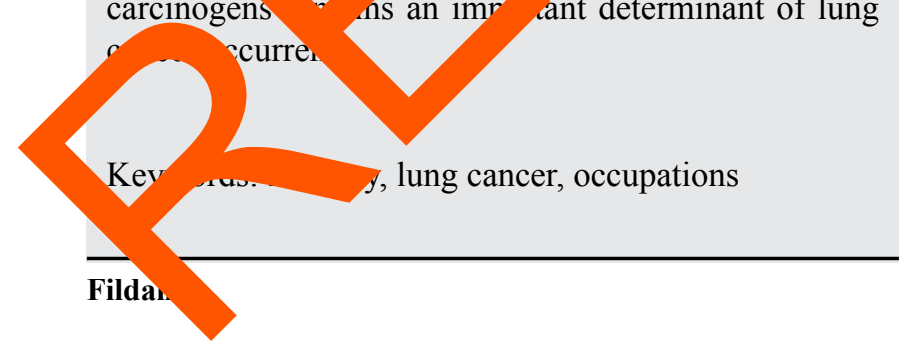

Clinical Pneumophtisiology Hospital of Constanta

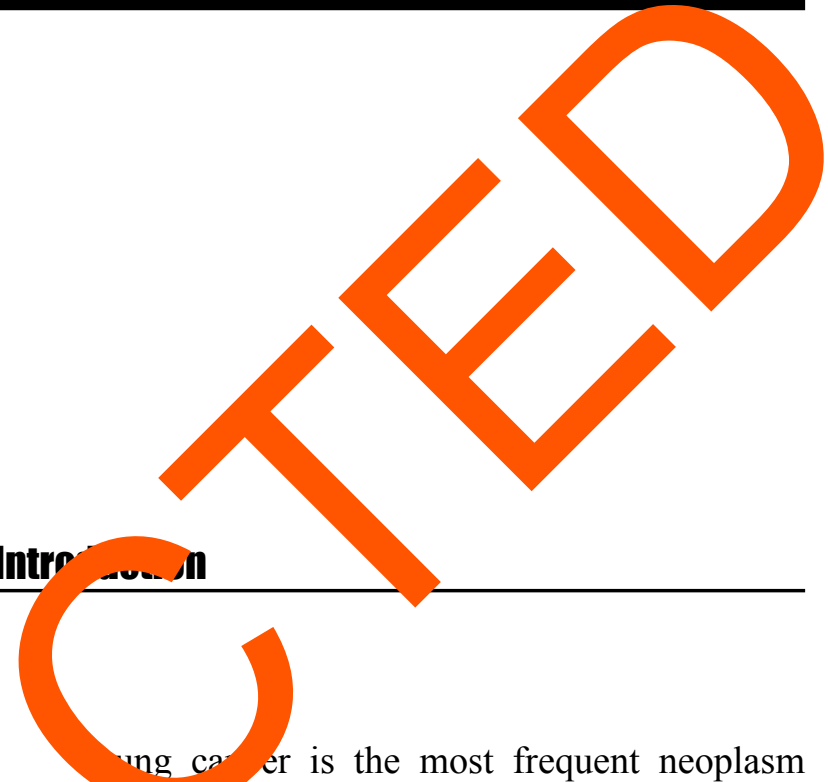
vorldwian, with more than 1.6 million new cases a million deaths in 2008 [1]. Although tobacco omoking is by large the most important cause, occupation is an important cause of lung cancer. It has been estimated that 13 to $29 \%$ of lung cancers in men are secondary to on-the-job exposure to chemicals and materials that increase the risk of lung cancer [2]. Many of these exposures are preventable through awareness, and taking appropriate precautions. In the year 2000 , it was estimated that $10 \%$ of lung cancer deaths among men (88,000 deaths) and 5\% among women $(14,300$ deaths) worldwide were attributable to exposure to 8 occupational lung carcinogens (arsenic, asbestos, beryllium, cadmium, chromium, diesel fumes, nickel, and silica) $[2,3,4]$. In Europe, assuming attributable fractions of $7 \%-15 \%$ (men) and $2 \%-9 \%$ (women), the estimated numbers of deaths caused by exposure to chemicals in the workplace were more than 29300 and 3200, respectively [2]. Prevalence of occupational exposure to carcinogens is still high: in 1990-1993, of almost 140 million workers in 15 states of the European Union, 32 million were estimated to be exposed to carcinogenic agents and about 7 million to the 8 above-mentioned carcinogens [5]. 
Different approaches are used to evaluate occupational exposure to carcinogens [6,7,8]: one makes use of lists of occupations known (list A) or suspected (list B) to be associated with lung cancer based on evaluations of carcinogenic risks by the International Agency for Research on Cancer (IARC) $[9,10]$. These lists are periodically updated and have been extensively used worldwide as a standardized tool to quantify the burden of occupational lung cancer $[8,11,12]$, but there remains a need to continue to evaluate occupations and try to uncover additional jobs and occupations that may contribute to the lung cancer burden.

\section{Objective}

The study aimed to analyze the ro ${ }^{1}$ of occupational exposures as a determinant of ng cancer risk. lung cancer in the Pneumology Departments of Constanta Clinical Pneumophtisiology Hospital and "Constantin Anastasatu" Pneumology Hospital of Ramnicu Valcea, between 2006 - 2010.

Extensive demographic and clinic ${ }^{1-2 n}$ were collected for lung cancer cases, includi morpho y coded according to the Internatic 1 Classificati of Diseases for Oncology, Third b ion [13] an categorized into major histol sc subty based $c$ World Health Organizatio nternational A ci- on for the Study of Lung $C$ cer clas cation [

All subject omp d self- ad inistered questionnaire re ding lit ne histr (years of start/stop, ind iob title) of $s$ a for at least 6 months. Ine , iries a job titles wo, coded following the International Stan 4 Industrial Classification of All r Activities 5] and the International St dard Classification of Occupations [16]. The co es were then anslated into occupations known (li A) or suspec d (list B) to entail a carcinogenic risk the lung ,10]. The list B occupation filling station an for which there are no specific was identified through text search. Subjects ith jow ritles from both lists were assigned to list A and to list B only if they had never worked in list A occupations.

We performed a statistical analysis by using the softs: GraphPad StatMate (1.01) and GraphPad Prism 4 (4.03).

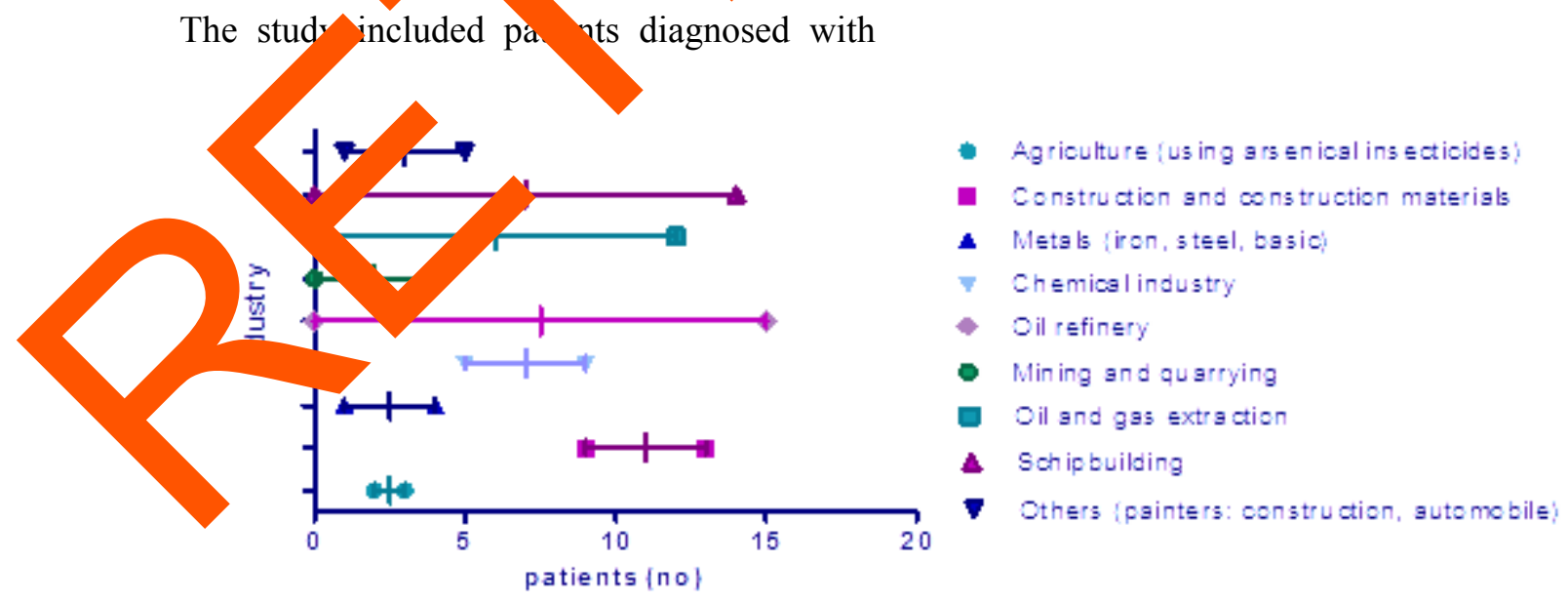

Figure 1 - Exposure to list A occupations 


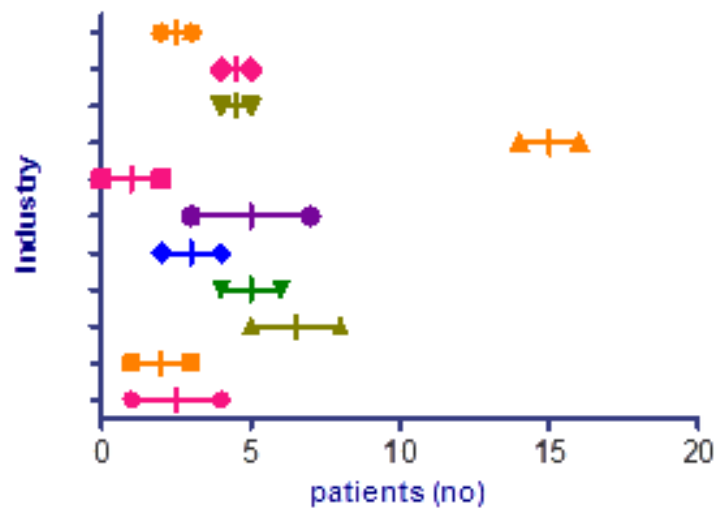

- Machine and equipments industry

- Leather (tanners, processors)

- Motor vehide manufacturing and repair

- Trade: filling station attendants

- Manufacture of fabricated vood products

- Rubberand plastics industry

- Printing (machine-rooms workers, print. ressmen)

* Transport ibus, truck drivers, railrond work

- Glass (glass vorkers, art glas ontainer and pressed vare)

- Food (butchers and mes rkers)

* Others flaunderers.

Figure 2 - Exposure to list B occur ons

\section{Results}

Of the 822 lung cancer cases registered in Pneumology Departments, during the 5-year $\mathrm{p}$ there were 478 patients from Constanta and 344 Ramnicu Valcea. The main characteristics of $1 \mathrm{~g}$ cancer patients are given in Table I.

Table I-Selected characteristics of ing cance patients

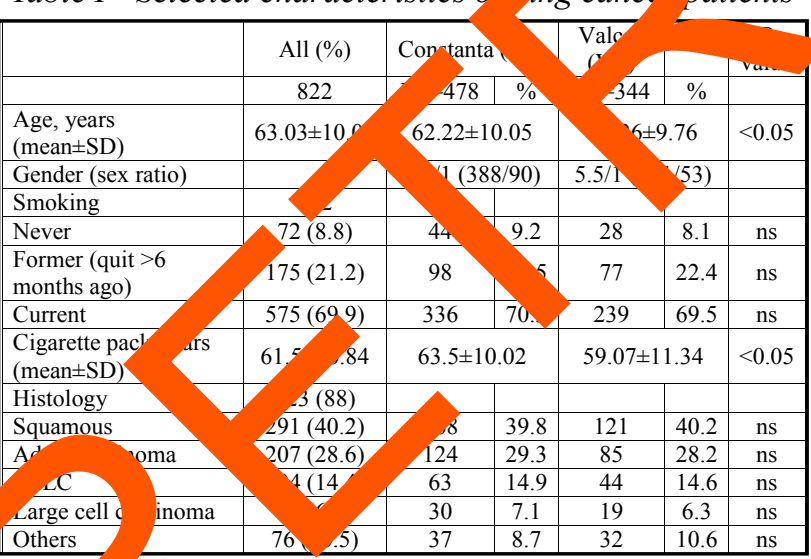

The patients from CT developed the disease at an lier age than patients from VL (62.22 versus 65.26 ars; $\mathrm{P}<0.05)$. Less than $10 \%$ of patients were never smokers (9.2\% CT group, $8.1 \% \mathrm{VL}$ group). Almost a fifth of the patients (175/822 cases) were former smokers. In both groups, about $70 \%$ of patients were current smokers but the patients from
CT groun had smokea eater numbers of cigarettes (63 ack-years versus 5, 7 pack-years, $\mathrm{P}<0.05$ ).

The majority of lung cancers were squamous ce carcinomas ( $.5 \%)$ in both groups.

Among all tients, 70 cases (14.64\%) from CT grou $_{\mathrm{P}} 27$ o $\mathrm{s}(7.84 \%)$ from VL group, had ever worked inno A occupations $(\mathrm{P}<0.05)$ (Table II). The 1) requent exposures in $\mathrm{CT}$ patients were in oil efinery (15 cases) and shipbuilding (14 cases). For VL group of patients, the exposures in constructions (9 cases) and chemical industry (9 cases) were more frequents.

Table II - The number and percentage of patients according to list A occupations

\begin{tabular}{|l|c|c|c|c|}
\hline \multicolumn{1}{|c|}{ Industry } & \multicolumn{2}{c|}{$\begin{array}{c}\text { CT group of } \\
\text { patients }\end{array}$} & \multicolumn{2}{c|}{$\begin{array}{c}\text { VL group of } \\
\text { patients }\end{array}$} \\
\hline & No & $\%$ & No & $\%$ \\
\hline $\begin{array}{l}\text { Agriculture (using arsenical } \\
\text { insecticides) }\end{array}$ & 2 & 0.41 & 3 & 0.87 \\
\hline $\begin{array}{l}\text { Construction and } \\
\text { construction materials }\end{array}$ & 13 & 2.71 & 9 & 2.61 \\
\hline Metals (iron and steel, basic) & 4 & 0.83 & 1 & 0.29 \\
\hline Chemical industry & 5 & 1.04 & 9 & 2.61 \\
\hline Oil refinery & 15 & 3.13 & 0 & 0 \\
\hline Mining and quarrying & 0 & 0 & 4 & 1.16 \\
\hline Oil and gas extraction & 12 & 2.51 & 0 & 0 \\
\hline Shipbuilding & 14 & 2.92 & 0 & 0 \\
\hline $\begin{array}{l}\text { Others (construction, } \\
\text { automobile painters) }\end{array}$ & 5 & 1.04 & 1 & 0.29 \\
\hline Total & 70 & 14.64 & 27 & 7.84 \\
\hline P value & & & $<0.05$ & \\
\hline
\end{tabular}

In total, 114 cases $(13.86 \%)$ : 56 cases $(11.71 \%)$ from CT group of patients and 48 cases $(13.95 \%)$ from VL group of patients had been working in 
occupations in list B, with no statistical differences between the two groups (Table III). We found a marked elevated exposure for bus and truck drivers in both groups (16 cases in CT group and 14 cases in VL group of patients). For women, we found increased level of exposure for launderers and dry cleaners ( 5 cases in both groups of patients).

Table III - The number and percentage of patients according to list $B$ occupations

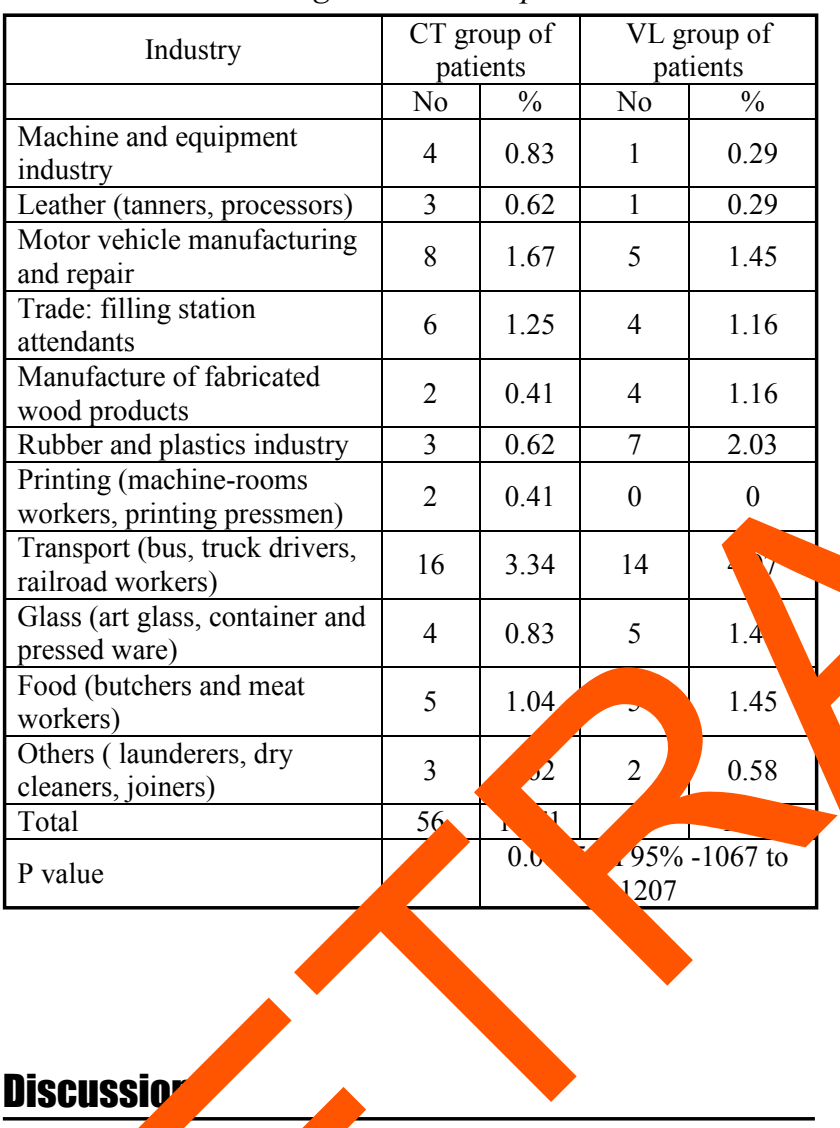

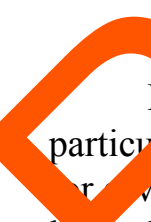

L g cance Adence in Romania [1] and, 1... in Constanta county is rising dramatically eral decaues. Although tobacco smoking is by la the most important cause, occupational factors play smarkable role.

Mis study was performed in 2005-2010 in Constanta, eastern Romania - one of the most populated, 724000 inhabitants, $65 \%$ living in urban areas, economically relevant, and industrialized region in Romania, high lung cancer incidence and mortality rates (higher than national rates) and in Valcea southwestern Romania, 412000 inhabitants, 55\% living in rural areas, lower incidence and mortality rates than national values, in order to analyze the role of occupational exposures as a detern ant $0_{2}$ ng cancer risk.

We found an exposure exco of $14.6 \%$ fo patients from Constanta ever loyed cupation known (list A) to be associ a with lung o cer, the largest contribution arom th sil refin and shipbuilding industries. pat as from Valcea, the frequency of exp are wa wer $\left(7.8^{\prime}, \mathrm{P}<0.05\right)$, with higher $c$ ributions fro co ructions and chemical in strio These findin are similar with results reported in ot studies $[17,18]$.

ical anal showed differences reg ding the exposure according with occupation list A $<0.05$ ).

Of the oc pations suspected (list B) to be ass 'ted with' hg cancer, we found a suggestive increas, truck drivers and railroad workers n) in both groups of patients, with no statistical (To s regarding the frequency of exposure $(\mathrm{P}=0.0885 \mathrm{CI} 95 \%-1067$ to 1207$)$. The findings for individual occupations in list B are suggestive because the number of exposed subjects was great. The increased risk for bus and truck drivers deserves mention because it was based on a substantial number of exposed workers (16 cases in Constanta and 14 cases in Valcea group of patients). For women, we found a moderate risk increase for launderers and dry cleaners, a finding reported in other studies [17].

This study confirmed the important role of past occupational exposures as a determinant of lung cancer risk at the beginning of the new century. The low exposure level for list A occupations among women was expected, given that exposure to most occupational lung carcinogens occurred in workplaces in which women constituted a minority.

In conclusion, the findings of this study confirm the need for continuous monitoring and improved control of work-related exposures, both for prevention and workers compensation purposes. Future occupational health studies should improve their ability to address interindividual variability in response to the lower exposures in work settings. 


\section{Eonclusions}

The frequency of exposure for patients from Constanta ever employed in occupations known to be associated with lung cancer (list A) was higher than the level of exposure for Valcea group of patients.

Over representation of oil refinery and shipbuilding industry exposure was observed in the group of patients from Constanta.

Of the occupations suspected to be associated with lung cancer (list B), the higher exposure was found for bus, truck drives and railroad workers, in both groups of patients.

\section{References}

1. Jemal, A., Siegel, R., Xu, J. \& W (2010 Cancer statistics 2010. Cance Clin, 0, 277 300.

2. Driscoll, T., Nelson, Dy. d Tee n14, n.m, al. (2005). The glob surden o isease due to occupational carci ans. Am J Im Yed, 48(6), 419-431.

3. Fingerhut, $M$ Nelson, D \& Driscoll, T. et al. (2006). $T$ contribution of o upational risks to the gl al burde of disease: summary and next steps Yed Lo ,7(2), 313-321.

4. Nelson, 1., Con d-Barrientos, M. \& D. oll, 1 al. (5 j5). The global burden of sele ed occu $_{1}$ al diseases and injury risks: $\mathrm{m}$ odology and summary. Am J Ind Med, $\checkmark(6), 400-18$.

5. Kauppinen, T., Toikkanen, J., Pedersen, D. et al. 05). Occupational exposure to carcinogens in the curopean Union. Occup Environ Med, 57(1), 10-18.

6. Mannetje, A. \& Kromhout, H. (2003). The use of occupation and industry classifications in general population studies. Int $J$ Epidemiol, 32(3), 419428

7. Teschke, K., Olshan, A.F. \& Daniels, J.L. et al. (2002). Occupational exposure assessment in case-control studies: opportunities for improvement. Occup Environ Me s9(y), 75593

8. Siemiatycki, J., Richardson, \& Boffett P. (2006) Occupation. A: Sc tenfeld I Fraumeni JF Jr, (Eds Cancer Ep. mio sy and Prevention, $3 r$ d. (pp. $2-35$. New York, NY: Oxford $\mathrm{Q}$ versi Press.

9. IARC Mon aphs the Ey aation of Carcinoge Risks to $h$ ans yon, France: Internat al ency for $\mathrm{R}$ arch on Cancer. Retrieved Octo 15, 2010, from http:// p aphs.iarc.th $\mathrm{NG} / \mathrm{Classification/index.}$ ohp.

10 Simonato, \& Saracci, R. (1983). Cancer, occupational a International Labor Organization LO), Ency spedia of Occupational Safety and H. 369-375. Geneva, Switzerland: ILO.

De Matteis, S., Consonni, D. \& Bertazzi, P.A. (3). Exposure to occupational carcinogens and lung cancer risk. Evolution of epidemiological estimates of attributable fraction. Acta Biomed, 79, 34-42.

12. Siemiatycki, J., Richardson, L. \& Straif, K. et al. (2004). Listing occupational carcinogens. Environ Health Perspect, 112(15), 1447-1459.

13. Fritz, A.G., Percy, C. \& Jack, A. et al. (2000). International Classification of Diseases for Oncology. 3rd ed. Geneva, Switzerland: World Health Organization.

14. Brambilla, E., Travis, W., Colby, T., Corrin, B. \& Shimosato, Y. (2001). The new World Health Organization classification of lung tumors. Eur $J$ Respir, 18(6), 1059-1068.

15. United Nations Publications. (1971). International Standard Industrial Classification of All Economic Activities (ISIC). (ST/STAT/M.4/ Rev.2/Add.1, Sales No.: E.71.XVII.8). New York, NY: Publishing Service, United Nations.

16. International Labor Office. (1968). International Standard Classification of Occupations. Geneva, Switzerland: International Labor Office.

17. Richiardi, L., Boffetta, P. \& Simonato, L. et al. 
(2004). Occupational risk factors for lung cancer in men and women: a population-based casecontrol study in Italy. Cancer Causes Control, 15(3), 285-294.

18. Pohlabeln, H., Boffetta, P. \& Ahrens, W. et al. (2000). Occupational risks for lung cancer among nonsmokers. Epidemiology, 11(5), 532-538. 